\title{
Microwave endometrial ablation (MEA) and bowel injury
}

Received: 20 October 2004 / Accepted: 4 January 2005 / Published online: 18 March 2005

(C) Springer-Verlag Berlin / Heidelberg 2005

\begin{abstract}
Microwave endometrial ablation (MEA) is regarded as an effective nonsurgical option for managing dysfunctional uterine bleeding (DUB). It is believed to be safe, quick, and easy to perform. To our knowledge, there has been only one reported case of a serious complication of a bowel injury during MEA. We report another similar case of accidental uterine perforation and bowel injury.
\end{abstract}

Keywords Microwave endometrial ablation -

Dysfunctional uterine bleeding $\cdot$ Menorrhagia

\section{Introduction}

Menorrhagia is a common clinical condition that can significantly affect quality of life [1]. The majority of women with this condition have dysfunctional uterine bleeding (DUB), in which abnormal bleeding occurs in a uterus that is of normal size and has no obvious pathology [2]. DUB constitutes a significant workload for the gynaecologist. Various medical treatments such as antifibrinolytics, cyclooxygenase inhibitors, and hormonal manipulation have been employed to treat DUB with varying success [3]. Surgery for DUB is generally performed when medical therapy fails [3]. Recently there have been increasing developments in hysteroscopic and

This paper was accepted as an oral communication in the 13th Annual Congress of the European Society of Gynaecological Endoscopy at Cagliari, Sardinia, Italy, 14-18 October 2004.

J. K. A. Jameel · T. Ahmed · J. V. T. Tilsed ( $\square)$

Department of General Surgery, Castle Hill Hospital, Castle Road, Cottingham, East Yorkshire, HU16 5JQ, UK

E-mail: jonathan.tilsed@hey.nhs.uk

Tel.: + 44-1482-875875

Fax: + 44-1482-623001

W. L. Noble $\cdot$ K. Phillips

Department of Obstetrics and Gynaecology, Castle Hill Hospital, Castle Road, Cottingham, East Yorkshire, HU16 5JQ, UK ablative techniques to treat this condition in order to minimise the number of hysterectomies performed [2]. One such technique is microwave endometrial ablation (MEA), which has a reported success rate of $83 \%$ and is believed to be safe, quick, and easy to perform [4]. It is well tolerated by patients and is believed to have fewer complications than the other current alternatives. To our knowledge there has been only one reported case in the literature of a serious complication of a bowel injury during this procedure [12]. We report another similar case in which accidental uterine perforation and bowel injuries were sustained during MEA. Fortunately, the injuries were immediately recognised, and timely surgical intervention led to complete recovery.

\section{Case report}

A 32-year-old woman, para 1, with no previous uterine or cervical surgery, was referred by her general practitioner for symptoms of irregular heavy periods for several years that had become worse when she was started on a progestogen-only pill for contraception about a year earlier. She was known to have hypothyroidism and was on thyroxine, and she had had one previous hospital admission for pelvic inflammatory disease. Abdominal and vaginal examinations and pelvic ultrasound were unremarkable. Hysteroscopy revealed a normal uterine cavity with thick menstrual endometrium with no evidence of polyps or fibroids.

After discussing with the patient the various treatment options for this condition, it was decided to perform MEA. The patient also expressed her wish to be sterilised at the same time. She therefore was scheduled for an MEA and a laparoscopic sterilisation. Goserelin $3.6 \mathrm{mg}$ was administered subcutaneously 5 weeks prior to the procedure in order to thin the endometrium. Uterine length was measured with a uterine sound. Dilatation of the cervix to $9 \mathrm{~mm}$ was performed with Hegar's dilators. Uterine length was checked again and found to be consistent with the first measurement. The 
microwave applicator probe was inserted and the measurement of uterine cavity confirmed, and the procedure was begun.

The MEA appeared uncomplicated, and the MEA temperature readings were within normal limits throughout the procedure. However, at laparoscopy a full-thickness burn to the posterior aspect of the uterus was identified. Because of this, the bowel was inspected following sterilisation, and it was evident that there were two burnt areas in the ileum-1 inch and 0.5 inch, 2 inches apart - and one burnt area in the antimesenteric edge of the sigmoid colon. Immediate general surgical help was sought, and after a full laparoscopy, laparotomy was performed. A loop of small bowel with the two burnt areas was resected, and a wedge resection of the affected part of the sigmoid colon was performed. Postoperatively the patient made an excellent recovery. Histological examination of the specimens revealed focal areas of necrosis in muscularis propria with submucosal oedema and focal mucosal damage in both the small bowel and in the wedge of sigmoid colon.

\section{Discussion}

Menorrhagia is a common clinical condition that accounts for most of the hysterectomies performed [5]. In England alone, over 40,000 hysterectomies are done each year [6], and overall in the United Kingdom it has been estimated that each woman has a $10 \%$ chance of having one by age 43 [7]. DUB is diagnosed when a woman suffers from abnormal uterine bleeding, usually menorrhagia during the reproductive years, that is unrelated to structural uterine abnormalities. Since its introduction in 1994 as a treatment for DUB, MEA has been widely studied in laboratory and clinical settings and is now regarded as an easy, efficacious technique with a low complication rate [8]. The technique involves delivery of high-frequency $(9.2 \mathrm{GHz})$ microwaves into the uterine cavity using an MEA applicator, which destroys the uterine endometrium up to a depth of 5-6 $\mathrm{mm}$, thereby reducing the menstrual blood flow [9]. Microwave energy to the MEA applicator is generated in an MEA control unit. This control unit has a microwave generator, a control module with an embedded microprocessor, and a user touch screen with a colour display [15].

An initial study on MEA reported a success rate of $83 \%$, with $57 \%$ of patients becoming amenorrhoeic and $26 \%$ experiencing light menstruation at 6 months [4]. Since then, numerous studies have been performed on the various aspects of outcome of this technique. MEA has been shown to be a well-tolerated procedure with an overall patient satisfaction rate of $83.7 \%$ at 3 years [10, 11] $70 \%$ of patients return to normal daily activity in 1 week and $95 \%$ of them do so in 3 weeks [11].

Because the microwave applicator is computer-driven, data from each treatment can be stored for analysis; therefore safety and efficacy studies can be undertaken.
In general, MEA is a safe technique. A review of 1,364 MEAs in 13 units in the UK reported four cases of blunt perforation, three during dilation with Hegar's dilators and one with the applicator in a retroverted uterus that was difficult to dilate. Only one serious complication ( $0.7 \%$ incidence) of an accidental small bowel burn in a patient who had had two previous caesarean sections was reported [8].

In our patient, similar damage, plus large bowel involvement, occurred during the procedure. Fortunately, our patient's injuries were recognised immediately and dealt with appropriately. The small bowel injuries were close to each other, and the portion of the bowel containing the two burnt areas was resected and end-to-end anastomosis performed. Sigmoid colon involvement was confined to the antimesenteric border, so a wedge of the sigmoid colon was removed without a formal resection. The patient recovered well with no postoperative complications.

Inadvertent injuries from the use of diathermy at laparotomy and laparoscopy have been well described. Diathermy, which has become an intrinsic part of modern day surgery, is reported to have an overall incidence of recognised injuries of between one and two patients per 1,000 operations [13]. Therefore, guidelines for appropriate use of diathermy and various safety measures have been established [14], and emphasis has been laid on training all staff involved in its use, including surgeons, anaesthetists, and theatre personnel. It is essential to also consider the use of MEA along the same lines. The National Institute for Clinical Excellence (NICE) has assessed the current evidence on the safety and efficacy of MEA and has supported its use provided normal arrangements are in place for consent, audit, and clinical governance [16]. NICE has also set definite guidelines on the use of MEA and patient information about the procedure [17].

The MEA system is designed to perform a thermal profile evaluation (temperature rise gate) at the start of each procedure to confirm performance of the MEA applicator and to detect profiles that may be associated with placing the MEA applicator outside the uterine cavity [15]. Any abnormal temperature signals on the monitor should be viewed with suspicion as they may indicate a uterine perforation, necessitating a hysteroscopy. Sounding the uterine cavity and dilating the cervical canal prior to the procedure should also be performed with caution, in particular with the acutely retroverted uterus, so as not to perforate the uterine wall. If the MEA applicator insertion depth and the preoperative sounding measurement differ, hysteroscopy should be performed to evaluate the cause of the apparent discrepancy [15].

Patients who develop complications may remain well with no systemic signs in the immediate aftermath of the event. The microwave burns reported here produced white plaques that were easily identified both at laparotomy and laparoscopy. There is currently insufficient evidence to justify routine laparoscopy after MEA. The 
senior authors are also aware of two other unreported cases of inadvertent MEA injuries within the UK. This raises concern over a possible underestimation of such injuries and emphasises the importance of maintaining a high index of suspicion for occasional procedural complications like the one described above. However, with appropriate and timely intervention when such complications occur, potentially dangerous consequences can be averted.

\section{References}

1. Kjerulff KH, Erickson BA, Langenberg PW (1996) Chronic gynecological conditions reported by US women: findings from the National Health Interview Survey, 1984-1992. Am J Public Health 86:195-99

2. Overton C, Maresh MJ (1995) Audit of currently available endometrial ablative techniques. Baillieres Clin Obstet Gynaecol 9:357-372

3. Munro MG (2001) Dysfunctional uterine bleeding: advances in diagnosis and treatment. Curr Opin Obstet Gynaecol 13:475489

4. Sharp NC, Cronin N, Feldberg I, Evans M, Hodgson D, Ellis S (1995) Microwaves for menorrhagia: a new fast technique for endometrial ablation. Lancet 346:1003-1004

5. Carlson KJ, Miller BA, Fowler FJ (1994) The Maine women's health study: 1. Outcomes of hysterectomy. Obstet Gynaecol $83: 556-565$

6. Department of Health (England) (2002) Hospital episode statistics. Finished consultant episodes by diagnosis, operation and speciality.
7. Kuh D, Stirling S (1995) Socio-economic variation in the admission for diseases of the female genital system and breast in a national cohort aged 15-43. BMJ 311:840-843

8. Downes E, O'Donavan P (2000) Microwave endometrial ablation in the management of menorrhagia: current status. Curr Opin Obstet Gynaecol 12:293-296

9. Feldberg IB, Cronin NJ (1998) A 9.2 GHz microwave applicator for the treatment of menorrhagia. In: Microwave symposium digest, 1998 IEEE MTT-S International, Baltimore, MD, 7-12 June 1998

10. Hodgson DA, Feldberg IB, Sharp N, et al. (1999) Microwave endometrial ablation: development, clinical trials outcomes at 3 years. Br J Obstet Gynaecol 106:684-694

11. Milligan MP, Etokowo G, Kanumuru S, Mannifold N (2002) Microwave endometrial ablation: patients' experiences in the 3 months following treatment. J Obstet Gynaecol 22:201-204

12. Jamieson R, Hammond I, Maouris P (2002) Small bowel perforation associated with microwave endometrial ablation. Aust NZ J Obstet Gynaecol 42:407-408

13. Nduka CC, Super PA, Monson JR, Darzi AW (1994) Cause and prevention of electrosurgical injuries in laparoscopy. $\mathrm{J} \mathrm{Am}$ Coll Surg 9:161-170

14. Aigner N, Fialka C, Fritz A, Wruhs O, Zoch G (1997) Complications in the use of diathermy. Burns 23:256-264

15. Microsulis Medical Ltd. Microwave endometrial ablation (MEA) - instruction for use. Document no. 62795/09/30

16. National Institute for Clinical Excellence (2003) IPG 7 Microwave endometrial ablation: guidance. National Institute for Clinical Excellence, London

17. National Institute for Clinical Excellence (2003) IPG7 Microwave endometrial ablation: understanding NICE guidance-information for people considering the procedure, and for the public. National Institute for Clinical Excellence, London 